\title{
Investigation on the Influence of Type of Steel Fibers on Shear Failure of HPFRCC Beams
}

\author{
Ehsan Nikbakht, Hugo Aureliano da Costa Gaspar, Rakan Mousa Jaradah and Muslich Hartadi Sutanto \\ Civil and Environmental Engineering Department, Universiti Teknologi PETRONAS, Malaysia
}

\begin{abstract}
This paper investigates the influence of different types of steel fiber on the mechanical properties of High Performance Fiber Reinforced Cementitious Composite (HPFRCC) as well as the shear failure mode of steel reinforced HPFRCC beams. Moreover, the influence of parameters such as span to effective depths $(\mathrm{a} / \mathrm{d})$ ratio of beams and longitudinal reinforcement ratio on shear strength of HPFRCC beams are examined. In reference to the results, despite the same tensile strength of both straight and hooked fibers utilized, the performance of straight steel fiber is superior to the hooked steel fiber due to its physiognomies. However, the beam specimens with straight steel fiber exhibit considerably lower deflection and ultimate load capacity when subjected to shear load. Also, the results show that the influence of type of steel fiber is more significant than the influence of longitudinal reinforcement ratio, i.e. the beam specimen with hooked steel fiber and $0.94 \%$ reinforcement ratio displayed higher deflection and ultimate shear load capacity compared to the specimen with straight steel fiber and $1.88 \%$ longitudinal reinforcement ratio.
\end{abstract}

\section{Introduction}

Conventional concrete performs well under compression, but it is very brittle, thus it fails under flexural and sudden loads. To suppress these flaws presented by the conventional OPC Concrete, a new cementitious composite, High Performance Fiber Reinforced Cementitious Composite (HPFRC) with enhanced mechanical properties was developed (Ganesan et.al, 2007; Yu et.al., 2014; Yoo \& Banthia, 2017). To suppress these flaws presented by the conventional OPC Concrete, engineers and scientists developed a new cementitious composite, High Performance Fiber Reinforced Cementitious Composite (HPFRC), composed by OPC, fine sand, quartz sand, Silica Fume, Fly ash, superplasticiser, water and steel fiber, which presents mechanical properties far superior compared to the conventional concrete and it is more durable (Yu et.al., 2014; Shin et.al., 2017). These superior mechanical properties of HPFRCC are mainly due to the increment in the bond between particles, the use of steel fibers and the low water-cement ratio in the mix design. By using different percentages of steel fibers in the mix design, researchers were able to prove that the HPFRCC has a greater strength, ductility and durability compared to the conventional concrete. HPFRC was developed in the 90s, and since then, many believe that HPFRC is one of the most promising construction materials because it is far superior to conventional concrete, as the constituents of HPFRC contribute most efficiently to the different structural requirements including strength, toughness, energy absorption capacity, durability, corrosion resistance and damage tolerance when subjected to large deformations in reinforced structural members (Parra-Montesinos 2005; Billington and Yoon 2004; Matthew et al. 2016). To achieve such superb mechanical properties, a more compacted microstructure is applied in the mix design, through the use of a low water-to-binder ratio (W/B), high-range water reducing agents, very fine admixtures, and high-volume content of steel fibers (Choudhary et.al., 2014; Eldin et. al., 2014; Russell and Graybeal, 2013). Apart from the enhancement in the mechanical characteristics, the HPFRCC differentiates from the conventional concrete because it does not contain coarse aggregate in its mix design. (Larrard and Sedran, 1994; Richard and Cheyrezy, 1995; Toledo et al. 2012). Often two types of steel fibers are used in the mix design - straight and twisted steel fiber. Moreover, studies conducted proved that the use of twisted steel fibers enhances the post cracking tensile strength and strain capacity, compared to straight and short steel fibers (Yoo et al. 2016). On the other hand, Shin and Mitchell (2017) stated that despite all the great advantaged that the steel fiber brings to the mixture; it can also become a problem, because it may create a nonhomogeneous mixture, and also reduce the workability.

To date, there are several studies conducted on behaviour of HPFRCC elements; however, there are limited research on the effect of type of steel fibers on behaviour of high-performance reinforced composites members. This study, investigates the influence of type of steel fibres on both mechanical properties of HPFRCC samples with different mix designs; and ultimate shear strength of reinforced HPFRCC beams. For this purpose, hooked and straight steel fibers are incorporated in various HPFRCC beams with different shear span-to-effective depth ratio (a/d) and longitudinal reinforcement ratio. 


\section{HPFRCC mix designs}

In this study, four different mix designs are used as shown in Table 1. Mix C, without steel fibre is used as a control mix, to compare with other mix designs with steel fibers. Mix A, Mix B and Mix D are casted with both straight and hooked steel fibers to study the impact of the different types of steel fibers on the mechanical properties of HPFRCC samples. The characteristics of straight steel fiber (SSF) and hooked steel fiber (HSF) used in this study are stated in Table 2.

Table 1. HPFRCC mix design used in this study.

\begin{tabular}{|c|c|c|c|c|}
\hline \multirow{2}{*}{$\begin{array}{c}\text { Ingredient } \\
\mathbf{( k g} / \mathbf{m} \mathbf{3})\end{array}$} & \multicolumn{4}{|c|}{ Mix Design } \\
\cline { 2 - 5 } & $\mathrm{A}$ & $\mathrm{B}$ & $\mathrm{C}$ & $\mathrm{D}$ \\
\hline Portland Cement & 600 & 700 & 700 & 600 \\
\hline Fly Ash & 450 & 450 & 450 & 450 \\
\hline Silica Fume & 50 & 78.75 & 78.75 & 78.75 \\
\hline Water & 194.45 & 194.25 & 194.25 & 194.45 \\
\hline River Sand & 480 & 480 & 480 & 480 \\
\hline Superplasticizer & 21 & 21 & 21 & 21 \\
\hline Steel Fiber & 117 & 117 & - & 117 \\
\hline Quartz Sand & 154.35 & 154.35 & 154.35 & 154.35 \\
\hline Water/Binder ratio & 0.185 & 0.185 & 0.185 & 0.185 \\
\hline
\end{tabular}

Table 2. Properties of steel fiber

\begin{tabular}{|l|l|}
\hline Straight Steel Fiber & Hooked Steel Fiber \\
\hline Specification: WSF0220 & Specification: C-GSF0325 \\
\hline Diameter: $0.2 \pm 0.05 \mathrm{~mm}$ & Diameter: $0.3 \pm 0.05 \mathrm{~mm}$ \\
\hline Length: $20 \pm 1 \mathrm{~mm}$ & Length: $25 \pm 1 \mathrm{~mm}$ \\
\hline Aspect Ratio (L/D): 100 & Aspect Ratio (L/D): 83 \\
\hline Tensile Strength: $>2300 \mathrm{MPa}$ & Tensile Strength: $>2300 \mathrm{MPa}$ \\
\hline
\end{tabular}

\section{Beam specimens}

In this paper, four reinforced HPFRCC beams with different longitudinal reinforcement ratio and different shear span to depth ratios of 2.0 and 3.5 as indicated in Table 3 are casted and experimented. The aim of the beam design is to analyze the influence of type of steel fibers on shear failure modes of the HPFRCC beams at different shear span to depth ratios $(\mathrm{a} / \mathrm{d})$. The dimensions and geometry of the beams are shown in Figure 1.

Table 3. HPFRCC beam specimens.

\begin{tabular}{|c|c|c|c|c|c|c|c|c|c|}
\hline Beam & As & $\mathbf{d}$ & $\mathbf{a}$ & $\mathbf{a} / \mathbf{d}$ & $\mathbf{L} 1$ & $\mathbf{L}$ & $\begin{array}{c}\text { Hooked } \\
\text { steel fiber }\end{array}$ & $\begin{array}{c}\text { Straight } \\
\text { steel fiber }\end{array}$ & $\begin{array}{c}\rho \\
(\%)\end{array}$ \\
\hline B1 & $2 \mathrm{D} 16$ & 280 & 540 & 2.0 & 300 & 1680 & & $\mathrm{X}$ & 1.34 \\
\hline B2 & $4 \mathrm{D} 12$ & 220 & 765 & 3.5 & 300 & 2130 & & $\mathrm{X}$ & 1.88 \\
\hline B3 & $2 \mathrm{D} 12$ & 220 & 765 & 3.5 & 300 & 2130 & $\mathrm{X}$ & & 0.94 \\
\hline
\end{tabular}




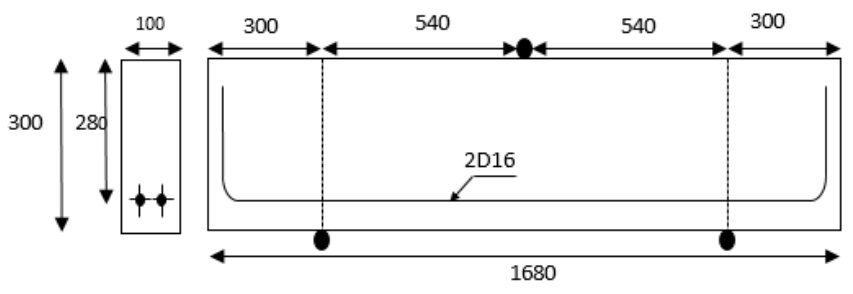

a) B1 specimen

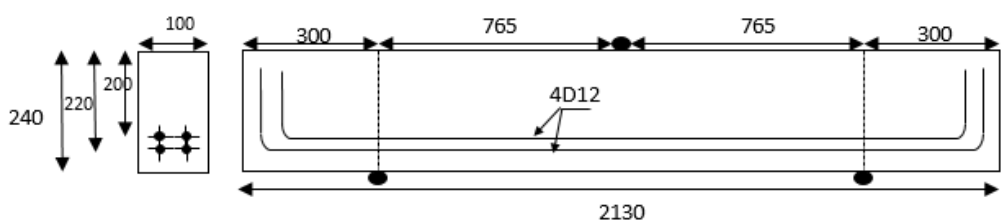

b) B2 specimen
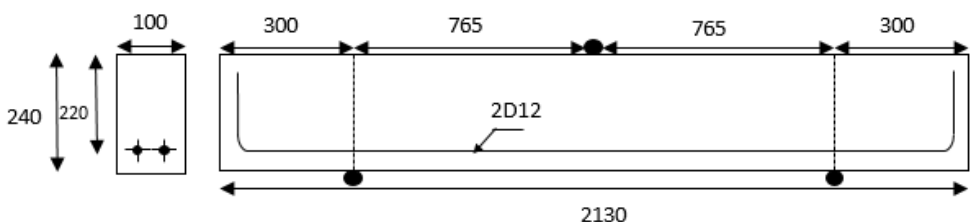

c) B3 specimen

Fig. 1. Dimensions and geometry of $\mathrm{B} 1, \mathrm{~B} 2$ and $\mathrm{B} 3$ specimens

\section{Results and Discussion}

\subsection{Mechanical properties}

In this study, both hooked and straight steel fibers were used to further understand the impact of the steel fibers in mix design. As shown in Figure 2, after 28 days of curing the mixtures containing straight steel fibers presented a greater compressive strength compared to the mix designs with hooked steel fiber. The compressive strength provided by the straight steel fiber increases by $22.47 \%$ in Mix A and by $1.64 \%$ in Mix B. This greater compressive strength is due to a more compact mix design that the straight steel fiber allows the mix to have due to the ends that they have, thus reducing the number of voids in the mixture. Figure 3 shows the flexural strength of the mixtures after 7, 14 and 28 days of curing. As can be seen from the figure, Mix C without steel fiber, has the lowest flexural strength compared to other samples, because of its high brittle nature. However, Mix B SSF, containing straight steel fiber, shows slightly higher flexural strength with 19.25 MPa versus 18.9 MPa strength of Mix B HSF with hooked steel fiber. 


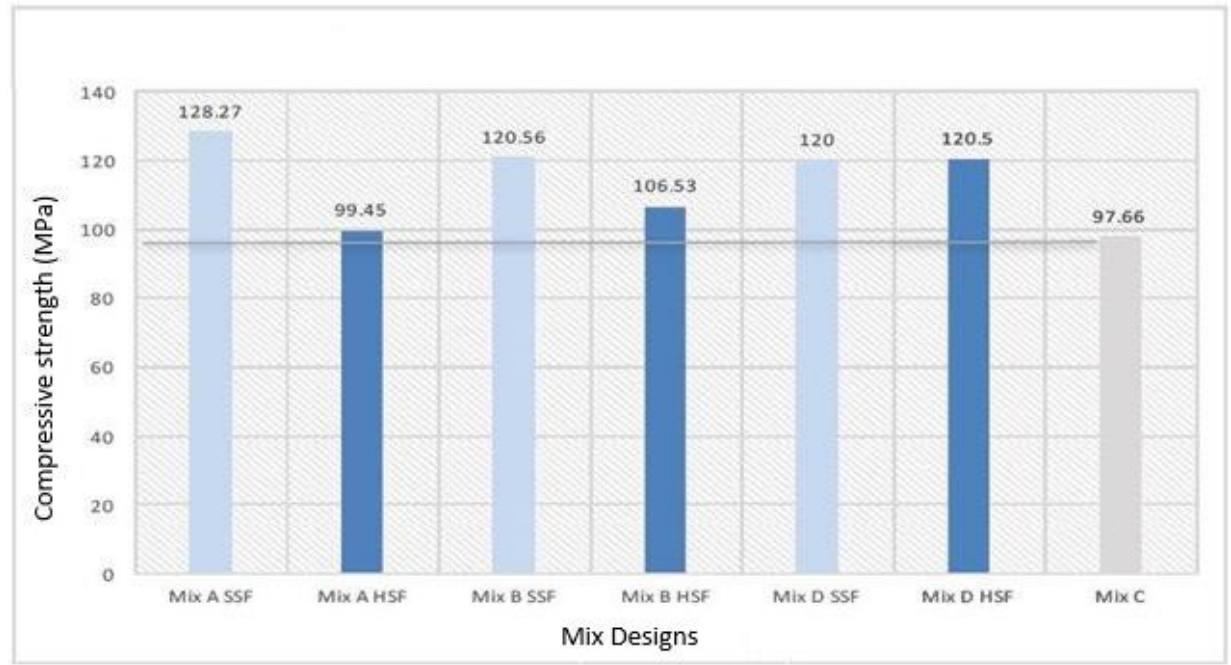

Fig. 2. Comparison of Compressive Strength with Different types of steel fibers

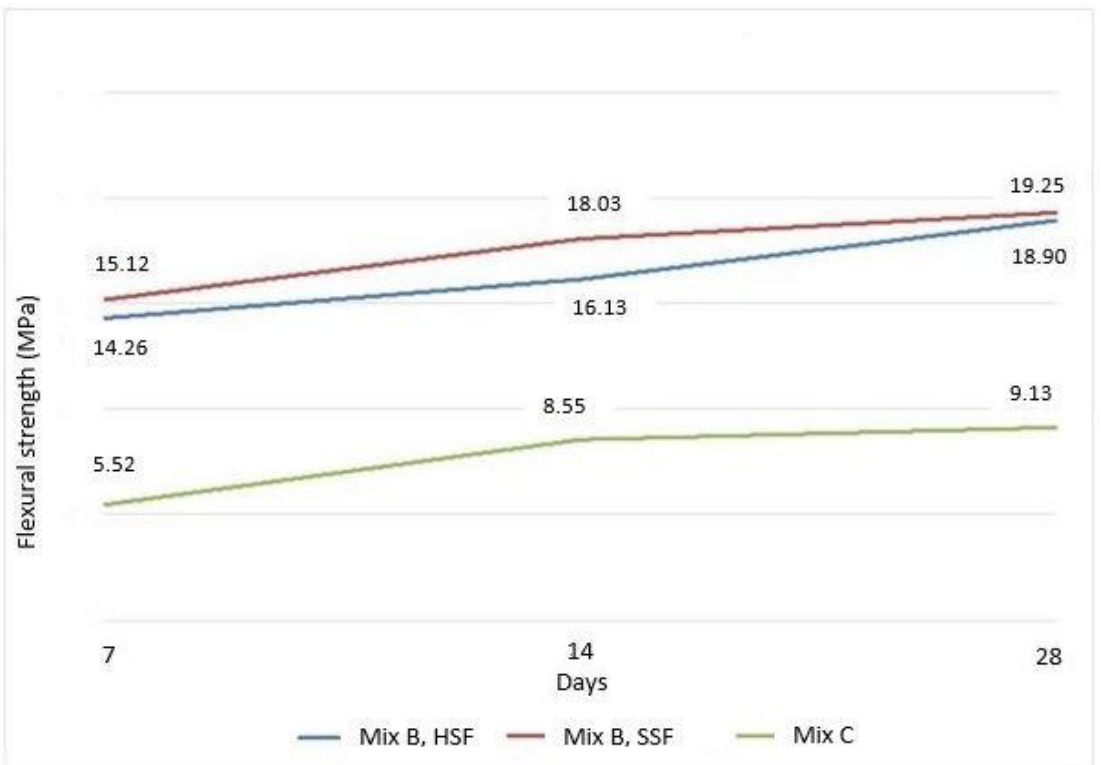

Fig. 3. Flexural strength of the samples with Mix B- Hooked steel fiber, Mix B- straight steel fiber and Mix C- non-steel fiber

\subsection{Shear strength of beam specimens}

In this section, the influence of type of steel fiber on shear failures of the four beams with different a/d and longitudinal reinforcement ratio $(\rho)$ are investigated. The HPFRCC mix design of D stated in Section 2, with the compressive strength of $120 \mathrm{MPa}$ are incorporated in the fabrication of all beam specimens. The results of the experimented beams are presented as follows.

The load-displacement of the specimen B1 with straight steel fiber (SSF) and hooked steel fiber (HSF) with a/d=2.0 are shown in Figure 4. The two beams experimented have the same design parameters such as the aspect ratio, length, effective depth, reinforcement size and mix design. As shown in the figure, the beam B1 casted with hooked steel fiber fails under the shear load of $278 \mathrm{kN}$, whereas the beam with straight steel fiber fails at the ultimate load of $198 \mathrm{kN}$. Also, with respect to the deflection capability, B1 specimen with hooked steel fiber exhibited slightly greater compared to the beam with straight steel fiber. Moreover, the failure modes of the beams are shown Figure 5. As can be observed from the figure, B1 specimen with hooked steel fiber failed due to shear cracks and concrete crush induced at the 
compression zone under the loading point, whereas B1 specimen with straight steel fiber failed mainly due to the shear cracks with large amount of crack opening induced.

Figure 6 presents the load-deflection response of the specimens B2 and B3 with a/d=3.5, but different longitudinal reinforcement ratio of $\rho=1.88 \%$ and $\rho=0.94 \%$. B2 has one layer of reinforcement and it has hooked steel fiber in its matrix. On the other hand, the specimen B3 has two layers of reinforcement and straight steel fiber in the matrix. Theoretically, with the increment of layers of reinforcement, the shear strength of the beams increases, because of the extra strength provided by the steel reinforcement. Nonetheless, throughout the experiments, it was noticed that the specimen B2, with one layer of reinforcement has a greater ultimate shear load compared to the specimen B3, with 2 layers of reinforcement. It can be concluded that this increment on the shear strength of approximately $29 \%$ is due to the superior shear resistance of hooked steel fiber used in the specimen B3. The concrete crush and failure modes of the specimens B2 and B3 are displayed in Figure 7. As can be observed from the figure, both specimens exhibited similar failure patterns with vertical concrete cracks across the height of beams; however, greater amount of concrete cracks opening occurred in specimen B2 with straight steel fiber.

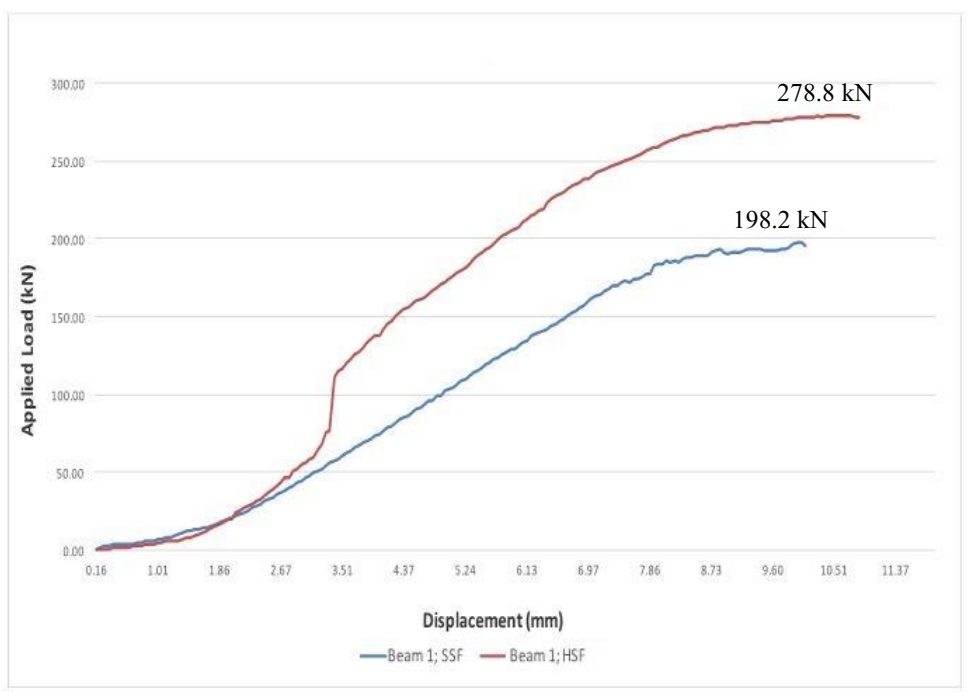

Fig. 4. Load-Displacement of B1 with straight steel fiber (SSF) and hooked steel fiber (HSF)

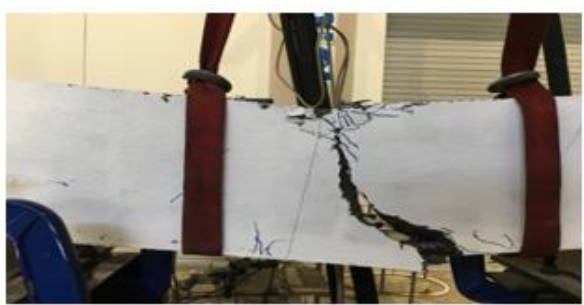

a) B1, with SSF

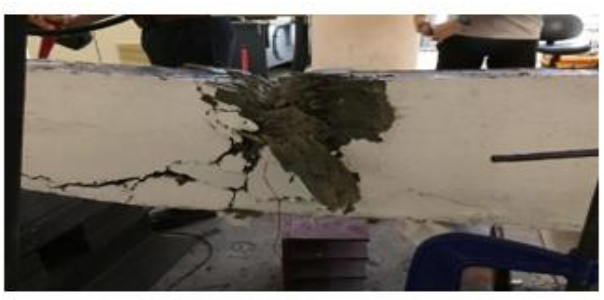

b) B1, with HSF

Fig. 5. Failure modes of B1 specimen: a) with straight steel fiber (SSF); b) with hooked steel fiber (HSF) 


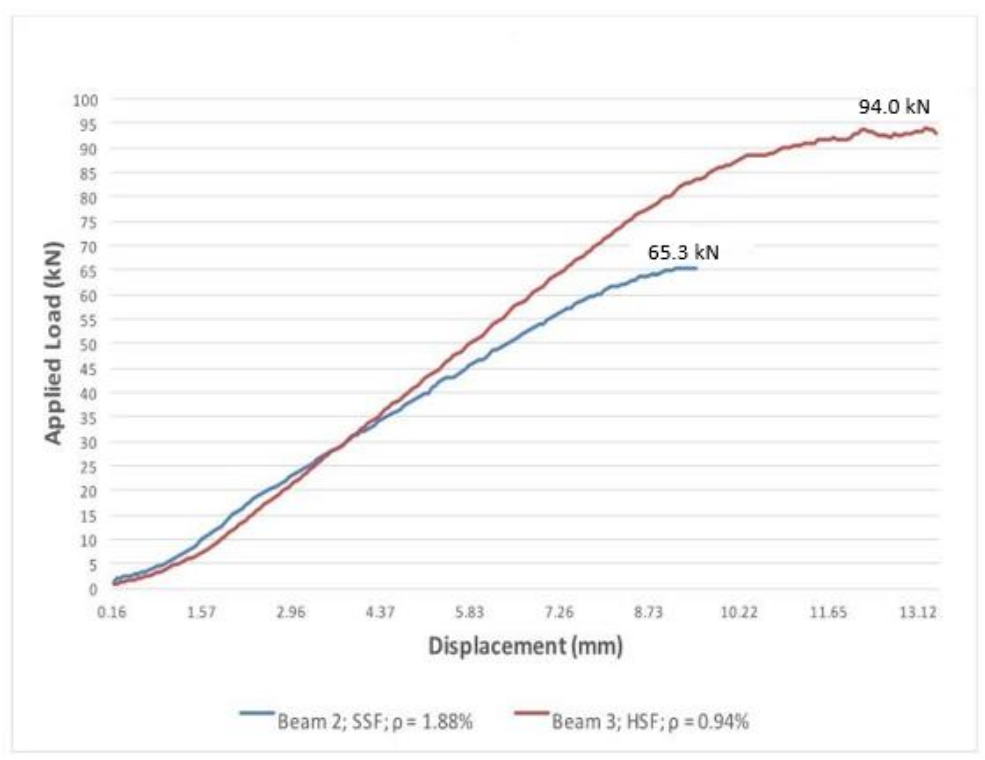

Fig. 6. Load-Displacement of B2 and B3 specimens

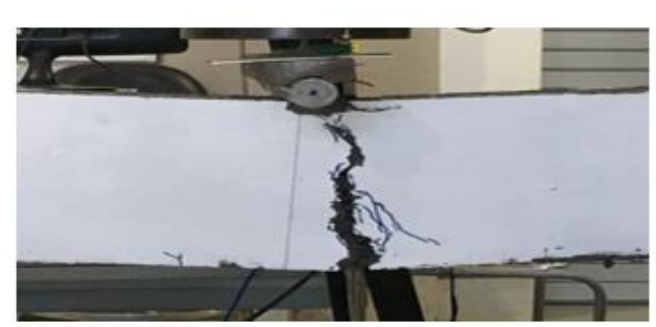

a) B2 specimen (SSF; $\rho=1.8 \%$ )

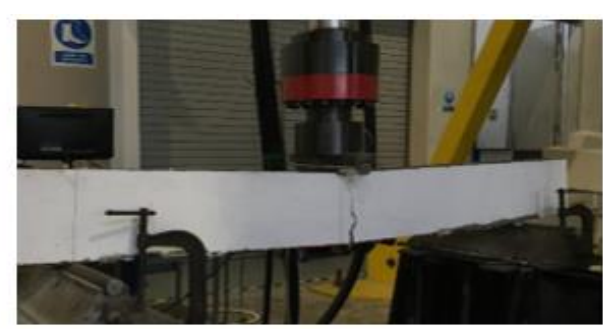

b) $\mathrm{B} 3$ specimen (HSF; $\rho=0.94 \%$ )

Fig. 7. Shear failures of specimens: a) B2; and b) B3

\section{Conclusions}

In this paper, the influence of type of steel fiber on mechanical properties as well as ultimate shear behaviour of HPFRCC beams were studied. Two types of straight and hooked steel fibers were used in order to investigate the loaddeflection response as well as failure modes of the beams with $\mathrm{a} / \mathrm{d}=2$ and 3.5 and longitudinal reinforcement ratios of $\rho$ $=0.94 \%$ and $1.88 \%$. Different HPFRCC mix designs were experimented and investigated. The HPFRCC mix design of $\mathrm{D}$ in this study with $120 \mathrm{MPa}$ compressive strength was incorporated to investigate the shear failure mode of the beams. The experimental results of HPFRCC mechanical properties showed that the performance of the samples with straight steel fiber is superior compared to the samples with hooked steel fiber, where the compressive, tensile and flexural strength of the cementitious composites are greater by $11 \%, 46 \%$ and $2 \%$, respectively. However, the experimental results of the beam specimens subject to shear load demonstrated that the beams with hooked steel fiber presents a greater ultimate load and deformation capacity for all beams with $\mathrm{a} / \mathrm{d}=2$ and 3.5. Moreover, the results showed that $\mathrm{B} 3$ specimen with hooked steel fiber and lower longitudinal reinforcement ratio $(\rho=0.94 \%)$ displayed greater shear strength and deformation capacity compared to the specimen B2 with straight steel fiber and higher longitudinal reinforcement ratio $(\rho=1.88 \%)$, which implies that the influence of type of steel fiber is more pronounced than the influence of longitudinal reinforcement ratio in HPFRCC beams subject to shear loads. 


\section{References}

1. S. Billington, and J. Yoon. Cyclic response of unbonded posttensioned precast columns with ductile fiberreinforced concrete. J. Bridge Eng., 10.1061/(ASCE)1084-0702(2004)9:4, 353-363 (2004)

2. S. Choudhary, R. Bajaj and R. K. Sharma. Study of high performance concrete. Civil Engineering and Environmental Technology, 1, 5, 109-113 (2014)

3. H. K. S. Eldin, H. A. Mohamed, M. Khater, and S. Ahmed. Mechanical Properties of Ultra-High-Performance Fiber Reinforced Concrete. International Journal of Engineering and Innovative Technology (IJEIT), 4, 4, 4-10, (2014)

4. N. Ganesan, P. V. Indira, and R. Abraham. Steel Fibre Reinforced High Performance Concrete Beam-Colum Joints Subjected to Cyclic Loading. Earthquake Technology, 44, 445-456 (2007)

5. F. Larrard, T. Sedran, Optimization of ultra-high-performance concrete by the use of a packing model, Cem. Concr. Res. 24, 997-1009 (1994)

6. J. Matthew Bandelt, and S. Billington. Impact of reinforcement ratio and loading type on the deformation capacity of high-performance fiber-reinforced cementitious composites reinforced with mild steel. J. Struct. Eng., 142, 10: 04016084 (2016)

7. G. Parra-Montesinos. "High-performance fiber-reinforced cement composites: An alternative for seismic design of structures.” ACI Struct. J., 102, 5, 668 (2005)

8. P. Richard, M. Cheyrezy, Composition of reactive powder concretes, Cem. Concr. Res. 25, 7, 1501-1511 (1995)

9. H. G. Russell, and B. A. Graybeal. Ultra-High-Performance Concrete: A State-of-the-Art Report for the Bridge Community. Report No. FHWA-HRT-13-060 (2013)

10. H. Shin, K. Min, and D. Mitchell. Confinement of Ultra-High-Performance Fiber Reinforced Concrete Columns. Composite Structures. 176:124-142 (2017)

11. R.D. Toledo Filho, E.A.B. Koenders, S. Formagini, and E.M.R. Fairbairn. Performance assessment of ultra-high performance fibre reinforced cementitious composites in view of sustainability, Mater. Des. 36, 880-888 (2012)

12. D.-Y. Yoo, and N. Banthia, Size-dependent impact resistance of ultra-high-performance fiber-reinforced concrete beams. Construction and Building Materials, 363-375 (2017)

13. D.-Y. Yoo, N. Banthia, and Y.-S. Yoon. Predicting the Flexural Behavior of Ultra-High-Performance FiberReinforced Concrete. Cement and Concrete Composites; 74, 71-87 (2016)

14. D.-Y. Yoo, S. Kim, G.-J. Park, J.-J. Park, and S.-W. Kim. Effects of fiber shape, aspect ratio, and volume fraction on flexural behavior of ultra-high-performance fiber-reinforced cement composites. Composite Structures; 174, 375-388 (2017)

15. R. Yu, P. Spiesz, and H. J. Brouwers. Mix design and properties assessment of ultra-high performance fibre reinforced concrete (UHPFRC). Cement and Concrete Research, 56: 29-39 (2014) 